\title{
The Use of Features from Fluorescence, Thermography, and NDVI Imaging to Detect Biotic Stress in Lettuce
}

\author{
Martin Sandmann, ${ }^{\dagger}$ Rita Grosch, and Jan Graefe, Leibniz-Institute of Vegetable and Ornamental Crops Großbeeren and Erfurt, Theodor- \\ Echtermeyer-Weg 1, 14979, Großbeeren, Germany
}

\begin{abstract}
Fluorescence, normalized difference vegetation index, and thermal imaging are three frequently used nondestructive methods to detect biotic stress in plants. Due, in part, to the inconsistent results reported in the literature and the lack of measurements on the whole-plant scale, we tested the suitability of a wide variety of variables obtained using these three imaging methods to classify young plants into biotically stressed and nonstressed plants. To this end, we applied the model plant-pathogen system lettuce-Rhizoctonia solani. The relevant data from each image and plant (healthy and diseased)

was extracted semiautomatically using sophisticated image processing algorithms. This method enabled us to identify the most appropriate variables via discriminant function and logistic regression analysis: photosystem II maximum quantum yield $\left(\mathrm{F}_{\mathrm{v}} / \mathrm{F}_{\mathrm{m}}\right)$ and fluorescence decline ratio can be used to classify variables with an error $\leq 0.052$. Lettuce seedlings with an $F_{v} / F_{m}$ ratio $>0.73$ were consistently healthy. In some cases, it was possible to detect infection prior to the appearance of symptoms. Possibilities to transfer the method to horticultural practice are discussed.
\end{abstract}

The early detection of the infection of plants with a pathogen using nondestructive methods is an important precondition for the precise, targeted control of pests and diseases in plant production systems. Such data can be used to minimize pesticide application rates instead of treating the entire crop in a field prophylactically (Cassman 1999). As such, the knowledge gained can help protect the environment and enhance the efficiency of the pesticide used; for example, by applying it at the right time (Bongiovanni and Lowenberg-DeBoer 2004; McBratney et al. 2005). Early diagnosis of infection is imperative for successful treatment but this is not always easy to achieve visually. Diseases are usually only visible at a very late stage in the pathogenesis when symptoms are expressed. For this reason, nondestructive, fast, and reliable methods are necessary to obtain this spatiotemporal information at early stage, enabling management actions to be taken that could inhibit further disease outbreak. Various imaging techniques are discussed in the literature, including fluorescence imaging (Bauriegel and Herppich 2014; Belasque et al. 2008; Chaerle et al. 2007a,b; Daley 1995), infrared thermography (Belin et al. 2013; Calderón et al. 2013; Chaerle et al. 2004; Costa et al. 2013; Nilsson 1991; Oerke et al. 2006), hyperspectral reflectance techniques (Mahlein et al. 2012), X-ray imaging, and nuclear magnetic resonance spectroscopy (Sankaran et al. 2010).

Various measurement scales are conceivable: leaf spot, leaf, plant, and crop. The first two scales may fail to detect infection because epidemic symptoms are not evenly distributed over a field crop at the early stage of a disease. The same situation of inhomogeneity arises on each individual plant (Oerke et al. 2006). However, one has to decide whether it is sufficient for measuring disease incidence (qualitative data) (Huang and Apan 2006) or severity (quantitative data) (Muhammed 2005) for the particular purpose.

Focusing on the Fusarium pathogen system in wheat, Bauriegel and Herppich (2014) were able to detect infections via hyperspectral and chlorophyll fluorescence imaging. Using laser-induced fluorescence spectroscopy, Belasque et al. (2008) discriminated not only between healthy and unhealthy citrus plants but also between mechanical and biotic stresses among the unhealthy plants. Fluorescence measurements

${ }^{\dagger}$ Corresponding author: M. Sandmann; E-mail: sandmann@igzev.de

Funding: The German Federal Ministry of Education and Research (BMBF) funded the project DiControl (031A560A).

Accepted for publication 3 December 2017.

@ 2018 The American Phytopathological Society have been used to detect sugar beet leaf spot disease (Cercospora beticola) (Chaerle et al. 2007a), cucumber mosaic (Cucumber mosaic virus) (Berdugo et al. 2014), apple scab (Venturia inaequalis) (Belin et al. 2013), and tobacco mosaic (Tobacco mosaic virus [TMV]) (Chaerle et al. 2007b). Infrared thermography has been used to detect diseases. Examples include Oerke et al. (2006) on cucumber downy mildew (Pseudoperonospora cubensis) and Chaerle et al. (2006) on tobacco mosaic (TMV) and on sugar beet leaf spot disease ( $C$. beticola). Using this method, spots with a higher temperature were observed in infested leaf areas and, consequently, a rise in temperature range within a leaf, which was ideal for detecting diseases. This temperature increase can be explained, in part, by reduced transpiration caused by an increased closure of stomata as well as changes in plant water relation. This is because some diseases (e.g., wilt disease) (Costa et al. 2013; Oerke et al. 2006) interrupt water and nutrient transport systems within the plant. On a very high spatial resolution, however, high-temperature spots can be related to local cell death, as observed by hypersensitive responses, a well-known plant defense mechanism for preventing the spread of infection by microbial pathogens (Greenberg 1997).

The application of nondestructive methods of early disease detection in lettuce bottom rot disease (Rhizoctonia solani) has not yet been described. $R$. solani is also responsible for diseases in a number of economically relevant crops. These include damping off in seedlings (Erlacher et al. 2014) such as radish, late root rot in sugar beet, and black scurf in potato. Bottom rot in lettuce is an example of a disease that is usually clearly visible at harvest. In the past, disease incidence has been determined visually on the basis of macroscopic symptoms (Grosch and Kofoet 2003). Therefore, the aim of our study is to determine whether infection of lettuce by $R$. solani can be detected at an early disease developmental stage using three imaging techniques: thermography, fluorescence, and reflectance (normalized difference vegetation index [NDVI]). Lettuce is more sensitive to pathogen infection than other plants at an early stage, inducing reduced growth (Grosch et al. 2011). We assume that the negative impact of the pathogen on growth is related to physiological changes that can be detected using imaging techniques. In contrast to most existing measures, detection was not performed on the scale of single leaves (Berdugo et al. 2014; Chaerle et al. 2007a; Daley 1995), leaf spots (Belin et al. 2013; Chaerle et al. 2007b; Scholes and Rolfe 2009), or canopies (Calderón et al. 2013) but on the scale of whole plants.

\section{Materials and Methods}

Experimental setup. The experiment was conducted under controlled cultivation conditions in a growth chamber (York, Mannheim, 
Germany). Lettuce seed (Lactuca sativa var. capitata 'Tizian'; Syngenta, Bad Salzuflen, Germany) was seeded in a sandy loam (unautoclaved, $45.6 \%$ sand, $28.6 \%$ clay [Kozlovskii et al. 2001], and $1.8 \%$ organic carbon content [Adam et al. 2014]) that originated from Golzow, Brandenburg (Germany). After a dark incubation period of $24 \mathrm{~h}$ at $6^{\circ} \mathrm{C}$ to induce germination, the basins were transferred to a growth chamber $\left(18^{\circ} \mathrm{C}, 80 \%\right.$ relative air humidity, $380 \mathrm{ppm} \mathrm{CO}_{2}$, $0 \mu \mathrm{mol} \mathrm{m} \mathrm{m}^{-2} \mathrm{~s}^{-1}$ photosynthetically active radiation [PAR]) until the first seedlings emerged. For the remaining experiment, cultivation conditions were set to 16 and $8 \mathrm{~h}, 60$ and $80 \%$ relative air humidity, and 20 and $15^{\circ} \mathrm{C}$, day and night, respectively; $420 \mu \mathrm{mol} \mathrm{m} \mathrm{m}^{-2} \mathrm{~s}^{-1}$ PAR; and 380 ppm $\mathrm{CO}_{2}$. In total, 21 basins ( 9.5 by 20 by $6 \mathrm{~cm}$ ) were prepared, with four rows by seven plants per basin and a resulting interplant spacing of $2.5 \mathrm{~cm}$. The lower half of each basin was filled with floral foam (mosy $\mathrm{GmbH}$, Thedinghausen, Germany) and covered with nonwoven fabric; the upper half was filled with the sieved soil. This floral foam served as a water buffer to ensure optimal water supply over the day. The plants were watered daily until a 5-mm surplus water layer appeared at the base of the basin. During the measurement period, the plants were watered after measurements had been completed each day. The soil was not additionally fertilized during the experiment. At Biologische Bundesanstalt, Bundessortenamt und Chemische Industrie $(\mathrm{BBCH})$ growth stage 10 (cotyledons completely unfolded) (Feller et al. 1995), a subset of 10 basins was inoculated with $R$. solani (AG1IB isolate 7/3/14) by placing nine barley kernels infected with $R$. solani (Schneider et al. 1997) at the base of the plants at a 1-cm soil depth on both narrow ends of the basins at a distance of $1.25 \mathrm{~cm}$ to the nearest plants. The barley kernels were prepared as follows: autoclaved three times in petri dishes, inoculated with potato dextrose agar bits where $R$. solan $i$ was grown for 3 days, and incubated for 21 days at $25^{\circ} \mathrm{C}$. The remaining untreated basins served as controls $(n=5)$ or as reference surfaces for thermography imaging $(n=$ 6 , see below).

Table 1. Variables measured or calculated from measurements taken using the fluorescence imaging system Open FluorCam (PSI 2012)

\begin{tabular}{ll}
\hline Symbol & \multicolumn{1}{c}{ Variable } \\
\hline $\mathrm{F}_{\mathrm{o}}$ & Minimum chlorophyll (Chl) fluorescence (dark-adapted) \\
$\mathrm{F}_{\mathrm{p}}$ & Peak Chl fluorescence (dark-adapted) \\
$\mathrm{F}_{\mathrm{t}}$ & Steady-state Chl fluorescence \\
$\mathrm{F}_{\mathrm{v}}$ & Variable Chl fluorescence (dark-adapted) \\
$\mathrm{F}_{\mathrm{v}} / \mathrm{F}_{\mathrm{m}}$ & Photosystem II maximum quantum yield, where $\mathrm{F}_{\mathrm{m}}$ is maximum \\
& Chl fluorescence (dark-adapted) \\
$\mathrm{R}_{\mathrm{fd}}$ & Chl fluorescence decline ratio in steady state \\
$\mathrm{R}_{\mathrm{NIR}}$ & Reflectance in far-red light $(740 \mathrm{~nm})$ \\
$\mathrm{R}_{\mathrm{RED}}$ & Reflectance in red light $(660 \mathrm{~nm})$ \\
$\mathrm{NDVI}$ & Normalized difference vegetation index \\
$\mathrm{F}_{440}$ & UV excited fluorescence at $440 \mathrm{~nm}$ (blue) \\
$\mathrm{F}_{520}$ & UV excited fluorescence at $520 \mathrm{~nm}$ (green) \\
$\mathrm{F}_{690}$ & UV excited fluorescence at 690 nm (red) \\
$\mathrm{F}_{740}$ & UV excited fluorescence at $740 \mathrm{~nm}$ (infrared) \\
$\mathrm{F}_{\mathrm{x}} \mathrm{F}_{\mathrm{y}}$ & Fluorescence ratios $\left(\mathrm{F}_{\mathrm{x}} / \mathrm{F}_{\mathrm{y}}\right)$, where $x$ and $y$ take a distinct value out \\
& of (440, 550, 690, 740) \\
\hline
\end{tabular}

Table 2. Variables measured or calculated from measurements taken using the thermography camera system

\begin{tabular}{ll}
\hline Symbol & \multicolumn{1}{c}{ Variable } \\
\hline $\mathrm{I}_{1}$ & Crop water-stress index (Jones 1999) \\
$\mathrm{I}_{2}$ & Crop water-stress index second version (Jones 1999) \\
$\mathrm{I}_{3}$ & Crop water-stress index third version (Jones 1999) \\
$\mathrm{T}_{\text {mean }}$ & Arithmetic mean temperature of the plant \\
$\mathrm{T}_{\text {median }}$ & Median temperature of all pixels per plant \\
$\mathrm{T}_{\text {range }}$ & $\begin{array}{c}\text { Range between pixels with maximum and minimum temperature } \\
\text { per plant }\end{array}$ \\
\hline
\end{tabular}

Measurements. Daily measurements were taken over a time scale of 5 days at $\mathrm{BBCH}$ growth stage 11 to 12 of lettuce (first to second true leaf unfolded). Three types of noninvasive, nondestructive, and noncontact measurements (Mahlein et al. 2012) were performed: fluorescence imaging, NDVI imaging, and thermography imaging. To obtain a test data set, the health condition of each plant was studied daily via visual rating. A plant was classified as "diseased" if at least one dark lesion was visible at the stem base, which is typically the first symptom after infection with $R$. solani; otherwise, it was classified as "healthy".

An Open FluorCam FC 800-O/2020 system (Photon Systems Instruments [PSI] spol. s r.o., Drasov, Czech Republic) with a dark adaptation box, placed directly inside the growth chamber, was used for fluorescence and NDVI imaging. Basins with dark-adapted plants (plants had been in the dark for at least since $5 \mathrm{~h}$ prior to measurements) or light-adapted plants (plants had been in the light for at least $2 \mathrm{~h}$ prior to measurements) were placed into the system and a number of fluorescence variables were captured (Table 1). In addition to actinic lights, an additional UV light panel (emitted radiation: $385 \mathrm{~nm}$ ) or a PAR/NDVI light panel (emitted radiation: 660 and $740 \mathrm{~nm}$ ) and several filters in front of the detecting camera were required to take the measurements. The thermography imaging system consisted of a VarioCam high-resolution bolometer-type camera (640 by 480 pixels, sensitivity of 9 to $14 \mu \mathrm{m}$; InfraTec $\mathrm{GmbH}$, Dresden, Germany), an objective lens (30-mm focal length; Jenoptik AG, Jena, Germany), and a 2-CCD camera system that obtains additional near-infrared (NIR) and red-green-blue (RGB) images over one optical path (JAI AD-130 GE; JAI Ltd., Yokohama, Japan). This camera system was vertically mounted inside the climate chamber to obtain nadir images of the target surfaces (i.e., plants). There were three basins on each image: two references (wet and dry on the left and right side of the image, respectively) and a central basin containing the measured plants. For the wet reference, the plants were sprayed with water until a film of water is formed on the leaves. This facilitated an estimate of maximum possible transpiration and, therefore, the minimum possible leaf temperature given the environmental conditions. The dry reference was created by spraying petroleum jelly onto the leaves. This prevented transpiration, facilitating an estimate of maximum possible leaf temperature (Jones 1999). The dry reference basin had to be rejected after being measured each day because the petroleum jelly caused the plants to die. Two images were made per sample basin, whereby the position of the dry and wet reference basins was switched to account for spatial variation. An overview of the variables obtained from the thermography system is provided in Table 2. Among other things, three crop water-stress indices based on Jones (1999) were tested:

$$
\begin{aligned}
& I_{1}=\left(T_{l}-T_{w e t}\right) /\left(T_{d r y}-T_{w e t}\right) ; I_{2}=\left(T_{l}-T_{w e t}\right) /\left(T_{d r y}-T_{l}\right) ; \\
& I_{3}=\left(T_{d r y}-T_{l}\right) /\left(T_{l}-T_{w e t}\right)
\end{aligned}
$$

where $T_{1}, T_{\text {dry }}$, and $T_{\text {wet }}$ are the leaf temperature and dry and wet reference temperatures, respectively. Jones (1999) emphasized that $\mathrm{I}_{2}$ is extremely sensitive to observations where $T_{1}>T_{\text {dry }}$. This situation and $\mathrm{T}_{1}$ approximately $=\mathrm{T}_{\mathrm{dry}}$ also occurred sometimes in our data, resulting in a very small denominator in $\mathrm{I}_{2}$ (equation 1 ) and, in turn, causing a vast variation of the index. Only data where $\mathrm{I}_{2}$ is in $(-100,100)$ was used for analysis, which meant the exclusion of 11 outlier plants, to confine variation of $\mathrm{I}_{2}$.

Image processing. Due to the large number of images taken on the five measurement days ( $>500$ images), a widely automated imageprocessing chain had to be established. For fluorescence and NDVI images, it was possible to use the FluorCam7 software (PSI spol. s r.o.) for segmentation (separation of plants and background) and plant-specific data acquisition. The strong contrast between plants and the background on the NDVI images was used to create a mask, giving each plant its location, surface, and identifier (Fig. 1). Using this mask, it was possible to segment fluorescence images with a high precision, although there is a low contrast for some measured variables. It was also possible to calculate the projected leaf area per plant and date from the number of pixels for each plant in the mask and a pixel size calibration using the known dimensions of the basin. Using 
this data, the absolute and relative daily leaf area growth rates per plant ( $\mathrm{A}_{\mathrm{abs}}$ and $\mathrm{A}_{\mathrm{rel}}$, respectively) were derived via

$$
\begin{aligned}
& A_{a b s}=A_{n}-A_{n-1} \\
& A_{r e l}=A_{a b s} A_{n}^{-1}
\end{aligned}
$$

where $A_{n}$ and $A_{n-1}$ are the projected leaf area in square millimeters per plant of the current day and previous day, respectively.

To segment the images of the thermography system, a new algorithm was developed using MATLAB and Image Processing Toolbox (release 2016b; The MathWorks Inc., Natick, USA). The first step was to perform a registration of the RGB, NIR, and thermography images, involving an alignment of resolution, perspective and orientation, and shifting (Gonzalez et al. 2010). The aim was to find the corresponding pixels in each kind of image of a basin. This is performed using a calibration plate, which has a number of common patches or targets that can easily be marked in the images of each spectral region. These so-called "control points" are selected manually via the MATLAB function CPSELECT. The control points are then used by the MATLAB function FITGEOTRANS to estimate the geometric transformation process to adjust unregistered images (NIR and RGB) to the fixed image (thermography). The transformation process itself is then performed by the MATLAB function IMWARP. For the final translation, again, some control points of the transformed and fixed image are selected (CPSELECT), and the transformed image is translated by the MATLAB function IMTRANSLATE, resulting in the registered image. Segmentation is carried out in the next step. Only the spectral information of the RGB image was used via the excess green variable $E x G=2 G-$ $R-B$, where $\mathrm{R}, \mathrm{G}$, and $\mathrm{B}$ are the red, green, and blue channels, respectively, of the RGB image. Unfortunately, similar reflectance properties of plants and the nonwoven fabric in the NIR waveband rendered the NIR channel useless for segmentation. The excess green algorithm produces ExG values between 0 and 255 for each pixel. Registered pixels with ExG values $>20$ were classified as leaves; otherwise, they were regarded as background.

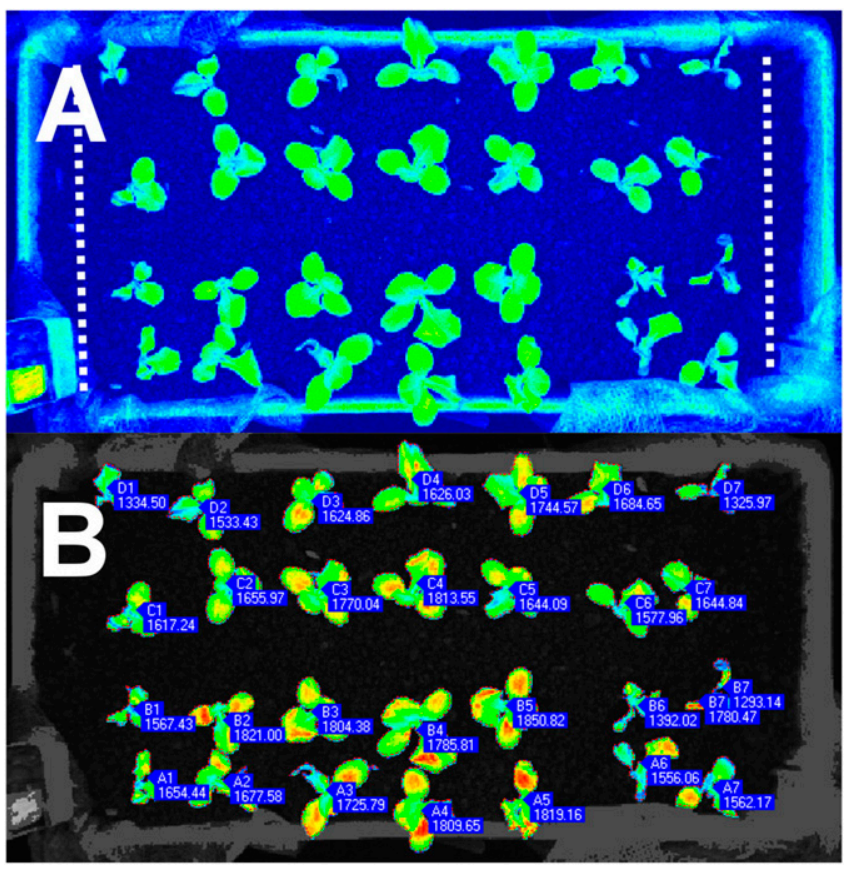

Fig. 1. Example of an inoculated basin for the segmentation of a normalized difference vegetation index NDVI image. A, Original measurement shows a strong contrast between plants and the background. Only small manual corrections are necessary for correct segmentation (e.g., overlapping of plant leaves, overlapping of plants, and the basin edge or weeds). White dotted lines show the locations of inoculation with Rhizoctonia solani. B, Segmented image with a label for each plant containing the identifier (rows $A$ to $D$ and columns 1 to 7 ) and the area in pixels.
The $k$-means algorithm based on Lloyd (1982) was used to assign each plant on the registered and segmented image to the correct column (Fig. 2). The $x$ values of the centroids of all plants were clustered into 12 groups for 100 times, and the cluster with the smallest sum of distances of all $x$ values from the corresponding group centroid was chosen. The row information was assigned via the ascending sorted $y$ values of the plant centroids per column (from 1 to 7 ).

Statistical methods. To account for possible boundary effects, only the central plants of each basin were included in the analysis. Those were the plants with the coordinates B3 to B5 and C3 to C5 on fluorescence images (Fig. 1B) and, accordingly, 6-3 to 6-5 and 7-3 to 7-5 on thermography images (Fig. 2B). In total, 445 plants were potentially suitable for analysis over all measurement dates. Of these, 22 plants were identified as outliers using a principal components analysis (SAS PROC PRINCOMP; SAS Institute 2008, Cary, NC). To obtain a dataset of assured healthy plants and assured diseased plants, only plants from noninoculated basins were considered healthy and only those plants with the rating diseased were considered diseased. The remaining dataset contained $n=221$ plants, including 132 healthy plants and 89 diseased plants. This dataset was analyzed via discriminant function analysis (SAS PROC DISCRIM; SAS Institute 2008) and validated using leave-one-out cross-validation (LOOCV). Discriminant function analysis was performed using data from all measurement dates and separately for each measurement date. Logistic regression analysis was also conducted using LOOCV (SAS PROC LOGISTIC; SAS Institute 2008).

\section{Results}

Means and standard deviations of all tested variables are given separately for both diseased and healthy plants in Table 3. In all, 18 of the variables show decreased and 15 show increased values

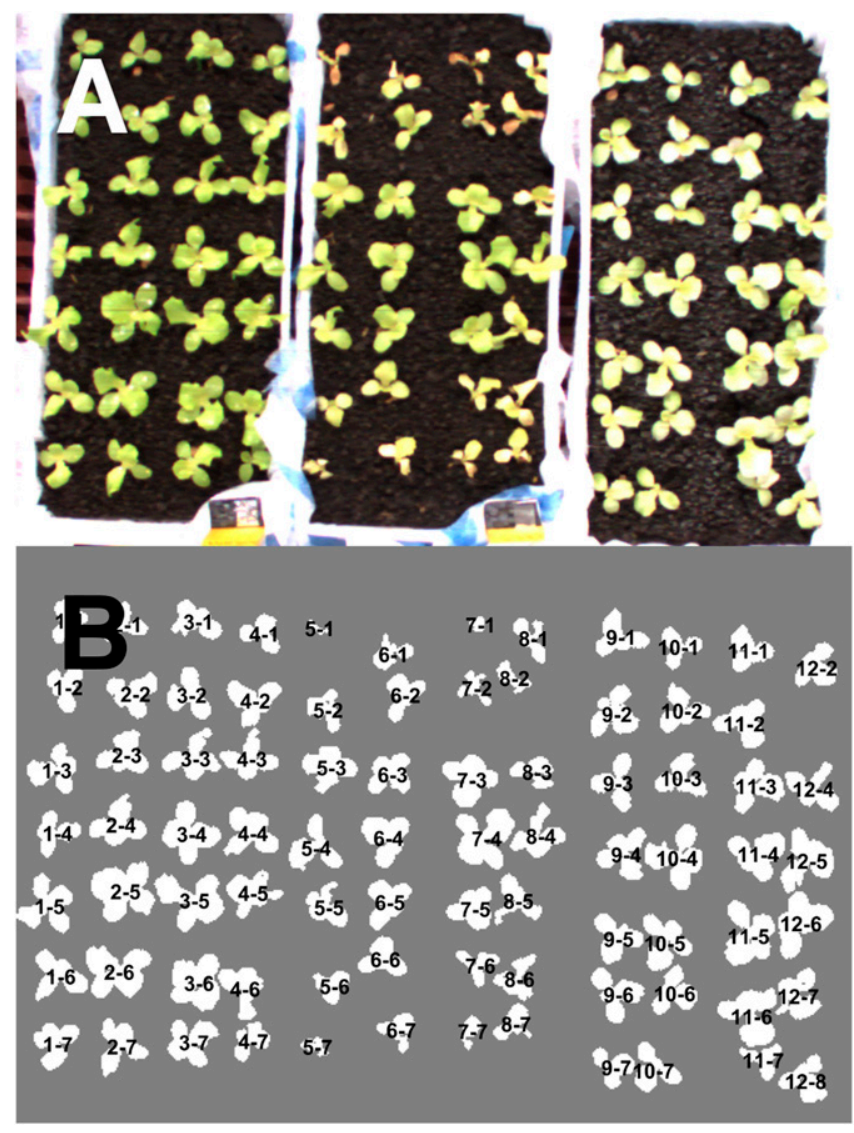

Fig. 2. Example of the segmentation of a thermography image. A, Red-green-blue image with three basins (from left to right): wet reference, measured basin, and dry reference, respectively. Similar manual corrections as for fluorescence images were necessary for optimal segmentation. B, Segmented image with a label for each plant containing the identifier (columns 1 to 12 and rows 1 to 7 ). 
for diseased plants. The variation among healthy plants over all variables is smaller than that among the diseased plants, because the means of standard deviations were 23.180 and 31.309 , respectively. Selected variables from discriminant function analysis and logistic regression analysis of the reduced dataset ( $n=221$ plants) are shown in Table 4. The Wilks' $\Lambda$ (codomain is [0,1]) was used as the criterion for deciding which variable discriminates the data best, whereby smaller values indicate better separation. The smallest $\Lambda$ was observed if the two variables fluorescence decline ratio in steady state $\left(\mathrm{R}_{\mathrm{fd}}\right)$ and variable chlorophyll fluorescence/maximum chlorophyll fluorescence $\left(\mathrm{F}_{\mathrm{v}} / \mathrm{F}_{\mathrm{m}}\right.$; photosystem II maximum quantum yield) are used for discrimination simultaneously. If they are used separately, $\Lambda$ is slightly higher for these two variables (Table 4 ), whereas the cross validation error $(E)$ is smaller for $F_{v} / F_{m}$ and higher for $R_{f d}$ compared with the simultaneous use of both variables. The five lowest $\Lambda$ were obtained by variables arising from fluorescence imaging. The NDVI still has an acceptable $\mathrm{E}(0.131)$ but $\Lambda(0.838)$ is relatively close to the upper limit. Crop water stress indexes $\left(\mathrm{I}_{1}\right.$ and $\left.\mathrm{I}_{2}\right)$ as well as $A_{\text {rel }}$ are less suited for discrimination because $E>0.3$ for all these variables. In particular, $I_{2}$ is the variable with the highest $\Lambda(=0.992)$ and $\mathrm{E}(=0.409)$ of all tested variables, which means that $\mathrm{I}_{2}$ provides no useful information for discriminating between diseased and healthy plants in this experiment. For the purpose of discrimination, variables from fluorescence images are superior to those from NDVI, thermography, and leaf area growth.

The general discriminant function for the two-dimensional model is

Table 3. Mean values ( $\overline{\mathrm{x}}$ ) and standard deviations (s) of all tested variables for diseased and healthy plants ${ }^{\mathrm{a}}$

\begin{tabular}{|c|c|c|c|c|}
\hline \multirow[b]{2}{*}{ Variable } & \multicolumn{2}{|c|}{ Healthy } & \multicolumn{2}{|c|}{ Diseased } \\
\hline & $\overline{\mathbf{x}}$ & $\mathbf{s}$ & $\overline{\mathbf{x}}$ & $\mathbf{s}$ \\
\hline $\mathrm{F}_{\mathrm{o}}$ & 51.67 & 4.79 & 56.02 & 10.49 \\
\hline$F_{p}$ & 246.53 & 27.58 & 165.40 & 41.92 \\
\hline $\mathrm{F}_{\mathrm{t}}$ & 80.51 & 7.79 & 77.25 & 16.50 \\
\hline $\mathrm{F}_{\mathrm{v}}$ & 194.86 & 24.24 & 109.37 & 34.74 \\
\hline $\mathrm{F}_{\mathrm{v}} / \mathrm{F}_{\mathrm{m}}$ & 0.78 & 0.02 & 0.61 & 0.06 \\
\hline $\mathrm{R}_{\mathrm{fd}}$ & 2.23 & 0.21 & 1.29 & 0.32 \\
\hline $\mathrm{R}_{\mathrm{NIR}}$ & 2470.08 & 151.95 & 2412.87 & 224.96 \\
\hline $\mathrm{R}_{\mathrm{RED}}$ & 914.13 & 390.28 & 1221.87 & 439.98 \\
\hline NDVI & 0.63 & 0.15 & 0.49 & 0.17 \\
\hline $\mathrm{F}_{440}$ & 387.59 & 9.53 & 449.17 & 59.10 \\
\hline $\mathrm{F}_{520}$ & 302.16 & 8.82 & 356.40 & 49.18 \\
\hline $\mathrm{F}_{690}$ & 217.16 & 11.07 & 212.65 & 18.24 \\
\hline $\mathrm{F}_{740}$ & 757.56 & 70.01 & 697.10 & 86.79 \\
\hline $\mathrm{F}_{440} \mathrm{~F}_{520}$ & 1.29 & 0.02 & 1.28 & 0.04 \\
\hline $\mathrm{F}_{440} \mathrm{~F}_{690}$ & 1.80 & 0.10 & 2.14 & 0.33 \\
\hline $\mathrm{F}_{440} \mathrm{~F}_{740}$ & 0.52 & 0.05 & 0.66 & 0.12 \\
\hline $\mathrm{F}_{520 \_} \mathrm{F}_{440}$ & 0.78 & 0.01 & 0.79 & 0.02 \\
\hline $\mathrm{F}_{520} \mathrm{~F}_{690}$ & 1.40 & 0.08 & 1.70 & 0.28 \\
\hline $\mathrm{F}_{520} \mathrm{~F}_{740}$ & 0.41 & 0.04 & 0.52 & 0.10 \\
\hline $\mathrm{F}_{690} \mathrm{~F}_{440}$ & 0.56 & 0.04 & 0.50 & 0.06 \\
\hline $\mathrm{F}_{690} \mathrm{~F}_{520}$ & 0.72 & 0.05 & 0.63 & 0.09 \\
\hline $\mathrm{F}_{690} \mathrm{~F}_{740}$ & 0.29 & 0.01 & 0.31 & 0.02 \\
\hline $\mathrm{F}_{740 \_} \mathrm{F}_{440}$ & 1.96 & 0.21 & 1.63 & 0.28 \\
\hline $\mathrm{F}_{740} \mathrm{~F}_{520}$ & 2.52 & 0.26 & 2.08 & 0.38 \\
\hline $\mathrm{F}_{740} \mathrm{~F}_{690}$ & 3.48 & 0.14 & 3.28 & 0.18 \\
\hline $\mathrm{I}_{1}$ & 0.87 & 0.16 & 1.00 & 0.16 \\
\hline $\mathrm{I}_{2}$ & 0.99 & 20.27 & 4.68 & 19.84 \\
\hline$I_{3}$ & 0.19 & 0.27 & 0.02 & 0.17 \\
\hline $\mathrm{T}_{\text {mean }}$ & 25.62 & 0.85 & 26.23 & 0.79 \\
\hline $\mathrm{T}_{\text {median }}$ & 25.62 & 0.85 & 26.18 & 0.82 \\
\hline $\mathrm{T}_{\text {range }}$ & 2.57 & 0.54 & 2.97 & 0.82 \\
\hline$A_{a b s}$ & 6.56 & 34.35 & -14.60 & 25.98 \\
\hline$A_{\text {rel }}$ & 0.02 & 0.20 & -0.14 & 0.26 \\
\hline
\end{tabular}

$$
y=\left[\left(c_{2}-c_{1}\right)-x\left(a_{1}-a_{2}\right)\right] /\left(b_{1}-b_{2}\right)
$$

where $\mathrm{a}_{1}, \mathrm{a}_{2}, \mathrm{~b}_{1}, \mathrm{~b}_{2}, \mathrm{c}_{1}$, and $\mathrm{c}_{2}$ are fitting parameters and $x$ and $y$ are the two variables used for the current model (e.g., $R_{f d}$ and $F_{v} / F_{m}$ ). The general logistic regression model is

$$
p(y=1)=1 /\left\{1+\exp \left[-\left(\beta_{0}+\beta_{1} x\right)\right]\right\}
$$

where $\beta_{0}$ and $\beta_{1}$ are fitting parameters, $x$ is the variable, and $y=1$ is the plant health state. One of the two possible states (diseased or healthy) has to be freely chosen. Here, $y=1$ means healthy. There would be no difference in $\mathrm{E}$ and Akaike information criterion (AIC) if diseased was chosen. In that case, the only thing that would change is the algebraic sign of the parameters of the logistic regression model. Finally, $p$ is the probability of the chosen state. The decision on which class a plant belongs to is realized by comparing the measured variable value of that plant to the relevant $y$ or $p$ of the discriminant function or logistic regression model. The fitting parameters of the two-dimensional model with the lowest $\Lambda$ are provided in Table 5 (Fig. 3B); the fitting parameters of the logistic regression models for $R_{f d}$ and $F_{v} / F_{m}$ are shown in Table 6 (Fig. 4).

This discriminant function (parameters from Table 5) was then applied separately to the data of those plants that were diseased during the experiment (i.e., they were not diseased on the first day of the visual rating but were diseased on the last day of the visual rating at the latest; $n=34$ plants). The dataset was further split according to the day of the first visual symptoms of an infection (day 0 ) and the days before and after that diagnosis. Some plants were rated from 3 days before and others until 3 days after visual symptoms. The proportion of daily correctly assigned classes is given in Table 7. This analysis shows that the model reliably predicts the health status of the plant 2 and 3 days before the occurrence of visual symptoms and on the days thereafter. There is some uncertainty on day 0 and the previous day because 15 and $17 \%$ of the plants were assigned to the wrong class by the model. Of particular interest are the five plants that were identified as diseased by the model on the day before day 0 . This fact shows that the model is able to identify infection before it can be detected by the human eye. On the other hand, five diseased plants were not identified by the model on day 0 .

Both $R_{f d}$ and $F_{v} / F_{m}$ are decreased in diseased plants (Fig. 3B). The development of $\mathrm{R}_{\mathrm{fd}}$ during the infection process is clearly shown in Figure 3A: most of the healthy plants have values $>2.0$ and most of

Table 4. Selected results of discriminant analysis and logistic regression analysis of all data from healthy plants (noninoculated basins) and diseased plants (all plants from inoculated basins that were rated as diseased) ${ }^{\mathrm{a}}$

\begin{tabular}{lcccrc}
\hline Measure & $\boldsymbol{\Lambda}$ & $\boldsymbol{P}$ & $\mathbf{E}_{\text {dis }}$ & \multicolumn{1}{c}{ AIC } & $\mathbf{E}_{\mathbf{l o g}}$ \\
\hline $\mathrm{R}_{\mathrm{fd}}+\mathrm{F}_{\mathrm{v}} / \mathrm{F}_{\mathrm{m}}$ & 0.185 & $<0.0001$ & 0.031 & 7.599 & 0.000 \\
$\mathrm{~F}_{\mathrm{v}} / \mathrm{F}_{\mathrm{m}}$ & 0.203 & $<0.0001$ & 0.026 & 5.616 & 0.000 \\
$\mathrm{R}_{\mathrm{fd}}$ & 0.242 & $<0.0001$ & 0.052 & 61.780 & 0.042 \\
$\mathrm{~F}_{\mathrm{v}}$ & 0.320 & $<0.0001$ & 0.058 & 72.060 & 0.058 \\
$\mathrm{~F}_{\mathrm{p}}$ & 0.421 & $<0.0001$ & 0.100 & 107.387 & 0.105 \\
$\mathrm{NDVI}$ & 0.838 & $<0.0001$ & 0.131 & 249.955 & 0.131 \\
$\mathrm{I}_{1}$ & 0.848 & $<0.0001$ & 0.350 & 199.043 & 0.350 \\
$\mathrm{~A}_{\text {rel }}$ & 0.892 & $<0.0001$ & 0.304 & 237.482 & 0.272 \\
$\mathrm{I}_{2}$ & 0.992 & 0.2560 & 0.409 & 215.752 & 0.396 \\
\hline
\end{tabular}

a $\Lambda=$ Wilks' $\Lambda, P=$ significance test of $\Lambda, \mathrm{E}_{\mathrm{dis}}=$ cross validation error from discriminant analysis, $\mathrm{E}_{\mathrm{log}}=$ cross validation error from logistic regression analysis, and AIC = Akaike information criterion from logistic regression analysis; for all other variables, see definitions in Tables 1 and 2.

Table 5. Parameters of the discriminant function of the two-dimensional model, including chlorophyll fluorescence decline ratio in steady state and photosystem II maximum quantum yield

\begin{tabular}{lrr}
\hline Parameter & \multicolumn{1}{c}{ 1 } & \multicolumn{1}{c}{$\mathbf{2}$} \\
\hline a & 487.773 & 420.147 \\
b & -16.777 & -23.628 \\
c & -172.046 & -113.449 \\
\hline
\end{tabular}


the diseased plants $<1.5$, whereby attention must be paid again to the low $\mathrm{R}_{\mathrm{fd}}$ values $<1.5$ in this figure on days after first symptoms $=-1$. The calculated thresholds for $\mathrm{R}_{\mathrm{fd}}$ below which a plant can be considered diseased are 1.72 and 1.76 using linear discriminant function and logistic regression, respectively. For the variable $F_{v} / F_{m}$, these figures would be 0.69 and 0.73 , correspondingly. The twodimensional discriminant function for $R_{f d}$ and $F_{v} / F_{m}$ is shown in Figure 3B.

Results from logistic regression analysis indicate that the lowest AIC is yielded by $F_{v} / F_{m}$ (Table 4). Using the two variables $R_{f d}$ and $\mathrm{F}_{\mathrm{v}} / \mathrm{F}_{\mathrm{m}}$ simultaneously leads to a slightly increased AIC (= 7.599); the use of $\mathrm{R}_{\mathrm{fd}}$ alone yields AIC $=61.78$. The increased AIC for $\mathrm{R}_{\mathrm{fd}}$ is caused by an overlap of the two health states (Fig. 4A), which also results in a gentle slope of the logistic regression model. In contrast, there is no overlapping of the data with $\mathrm{F}_{\mathrm{v}} / \mathrm{F}_{\mathrm{m}}$ (Fig. 4B) and almost no gap between diseased and healthy plants; hence, there is a smaller AIC and a steep slope of the logistic regression model.

\section{Discussion}

The observed decrease in $F_{v} / F_{m}, R_{f d}$, NDVI, $A_{a b s}$, and $A_{\text {rel }}$ (Table 3) in diseased plants was expected, because diseased plants have a smaller green leaf area and, therefore, are less vital. In addition, the increase in $I_{1}$, arithmetic mean temperature of the plant, and temperature range between pixels with maximum and minimum temperature per plant ( $\left.T_{\text {range }}\right)$ is also caused by the formation of necrotic tissue, which prevents transpirational cooling. This agrees with the findings of Oerke et al. (2006), who observed the same behavior of $\mathrm{T}_{\text {range }}$ with cucumber downy mildew ( $P$. cubensis). Our results show that it is possible to detect infections of $R$. solani in lettuce seedlings using optical methods. In particular, fluorescence imaging is ideal for this purpose because it results in the most correct classification of plants (Table 4). Thermography-based variables were not expected to be inferior in this context because thermography is frequently reported to work very well, even in presymptomatic disease detection. Examples include studies by Chaerle et al. (1999) for TMV (leaves), Lindenthal et al. (2005) for $P$. cubensis (leaves), and Boccara et al. (2001), for Nicotiana sylvestris and Erwinia amylovora.

The two statistical methods used in this study to classify the dataset produced comparable results that differed slightly in detail. With regard to these two methods, $\mathrm{F}_{\mathrm{v}} / \mathrm{F}_{\mathrm{m}}$ and $\mathrm{R}_{\mathrm{fd}}$ are the two most appropriate variables tested to identify diseased plants. Because $F_{v} / F_{m}$ has a lower $\mathrm{E}$ in the analysis methods and a lower AIC in logistic regression analysis, this variable might be preferred. The simultaneous use of these two variables in discriminant function analysis yields the lowest $\Lambda$. However, little additional information is gained compared with using just one of these variables, given that they are significantly correlated $\left(r_{\text {adj }}^{2}=0.834, P<0.0001\right)$. To keep the analysis as simple and precise as possible, the logistic regression analysis with variable $F_{v} / F_{m}$ and the parameters from Table 6 can be recommended for classification. This finally translates into a threshold of $\mathrm{F}_{\mathrm{v}} / \mathrm{F}_{\mathrm{m}}>0.73$ for detecting healthy lettuce plants under $R$. solani infection pressure. The choice of $\mathrm{F}_{\mathrm{v}} / \mathrm{F}_{\mathrm{m}}$ is consistent with the vast majority of the literature (Cséfalvay et al. 2009; Iqbal et al. 2012; Muniz et al. 2014) where, for example, Tatagiba et al. (2015) did not detect a decreasing $\mathrm{F}_{\mathrm{v}} / \mathrm{F}_{\mathrm{m}}$ in rice leaves infected with Monographella albescens.

Stress detection prior to the occurrence of visual symptoms using fluorescence and thermal imaging is reported by Chaerle et al. (2004), and was also observed in our experiment. Manually rated plants were only classified as diseased when distinct symptoms of $R$. solani were present. In all other cases, plants were rated as healthy (i.e., slightly dark shadows on the hypocotyl, leaves with a slightly lighter shade of green, and slightly limp leaves). These leaf physiological conditions, which are precursors to the appearance of symptoms, were recognized in most of the plants that had been detected as diseased by fluorescence imaging the day before distinct symptoms appeared (Table 7). Therefore, the method is capable of reliably detecting $R$. solani infection earlier than the human eye. It may seem confusing that the relative proportion of wrongly assigned class memberships on day 0 in Table 7 (0.150) is much higher than cross validation error from discriminant analysis $\left(\mathrm{E}_{\mathrm{dis}}\right)$ from the model calibration in Table 4 (0.031). However, this phenomenon is due to databases differing from $n=191$ for calibration, where 6 plants were

Table 6. Parameters of the logistic regression model for variables chlorophyll fluorescence decline ratio in steady state $\left(\mathrm{R}_{\mathrm{fd}}\right)$ and photosystem II maximum quantum yield $\left(\mathrm{F}_{\mathrm{v}} / \mathrm{F}_{\mathrm{m}}\right)$

\begin{tabular}{lrr}
\hline Parameter & $\mathbf{R}_{\mathbf{f d}}$ & $\mathbf{F}_{\mathbf{v}} / \mathbf{F}_{\mathbf{m}}$ \\
\hline$\beta_{0}$ & -15.5 & -200.8 \\
$\beta_{1}$ & 8.8 & 274.1 \\
\hline
\end{tabular}
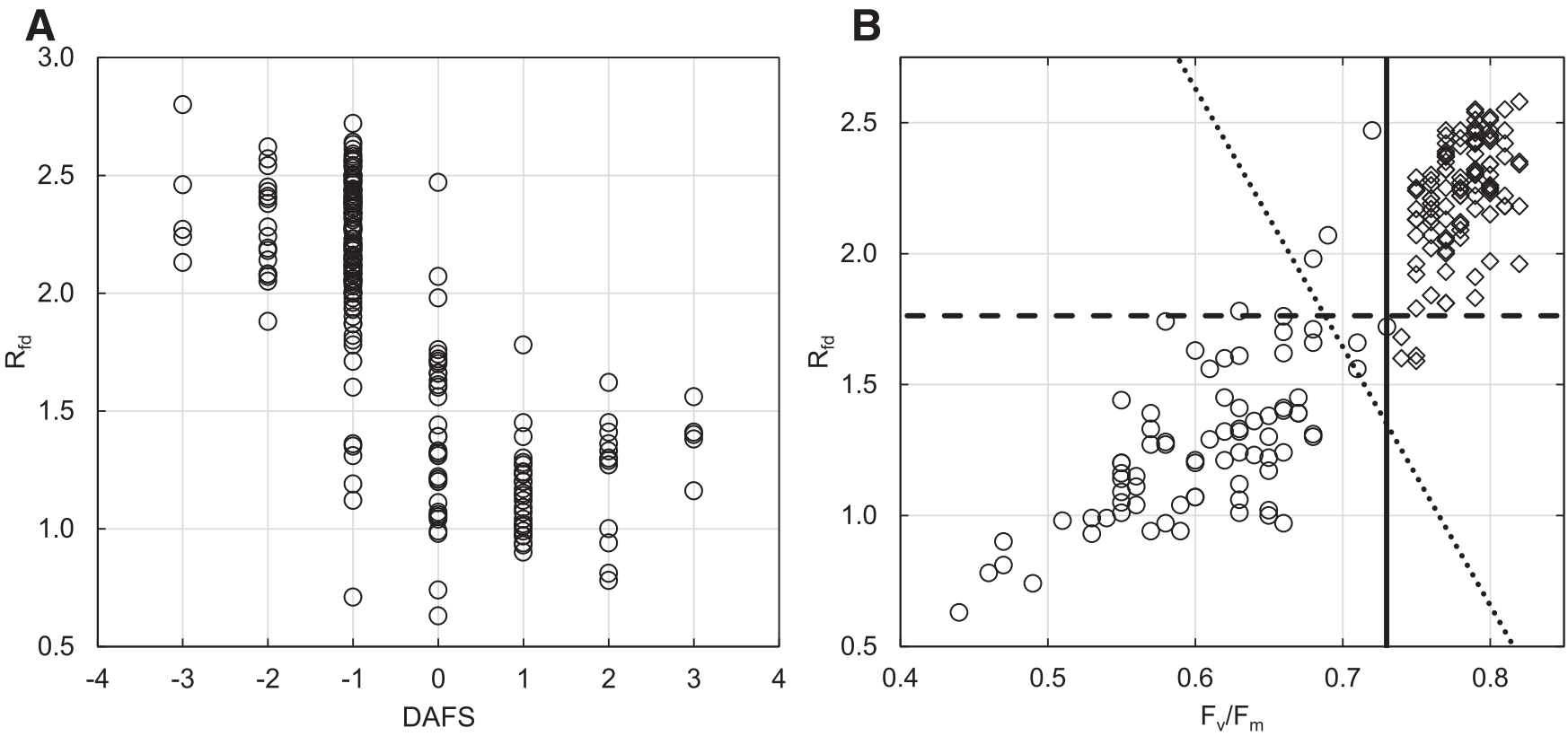

Fig. 3. A, Days after first symptoms (DAFS) against fluorescence decline ratio in steady state $\left(R_{\mathrm{fd}}\right)$. DAFS $=0$ is the first day on which symptoms could be detected visually; $n=215$. $\mathrm{B}$, photosystem II maximum quantum yield $\left(\mathrm{F}_{\mathrm{v}} / \mathrm{F}_{\mathrm{m}}\right)$ against $\mathrm{R}_{\mathrm{fd}}$. Circles = diseased, diamonds = healthy, dotted line = discriminant function using the parameters from Table 5 , dashed line $=$ threshold for $R_{\mathrm{fd}}$ from logistic regression, and solid line = threshold for $F_{\mathrm{v}} / F_{\mathrm{m}}$ from logistic regression; $n=191$. 
assigned to the wrong class; and $n=34$ for day 0 , where 5 of the 6 wrongly assigned plants from the calibration database are included in this analysis. $\mathrm{E}_{\mathrm{dis}}$ is calculated as the weighted mean of the error proportions for both classes. There were 78 diseased plants, 6 of which were assigned wrongly (proportion $=0.077$ ), and 113 healthy plants, none of which was assigned wrongly (portion $=0.000$ ). Hence, $\mathrm{E}_{\text {dis }}=(0.000 \times 113+0.077 \times 78) / 191=0.031$.

Difficulties were encountered in separating plants from each other. In particular, the relatively small distance between plants meant that painstaking manual corrections had to be made to separate plants with overlapping leaves. In the future, however, one possible solution could be to increase plant distance for measurements on the single-plant scale or to decrease it for measurements on a sectorial scale with small groups of overlapping plants, which would result in a decrease in spatial resolution.

Because the two favored variables $\mathrm{R}_{\mathrm{fd}}$ and $\mathrm{F}_{\mathrm{v}} / \mathrm{F}_{\mathrm{m}}$, need to be measured on dark-adapted plants, it would be difficult to introduce this method for detecting infections from a controlled environment into horticultural practice in the greenhouse or even in the field. One approach could be to take measurements at night, which could be performed automatically in a greenhouse using a box (without an underside; including light sources, fluorescence camera system, $\mathrm{CPU}$, and memory) that is transported along tables using a special construction and placed over some of the basins for each measurement. The box would avoid or diminish stray light from the excitation flash of chlorophyll fluorescence, which could influence neighboring plants. The next morning, the producer would have information on which plants are diseased and could apply all cultivation methods as required. In addition, the usual cultivation methods could be applied without interruption, because no measurements are taken during the day. One first step in this direction is described by Schor et al. (2017), who developed a nondestructive robotic detection system for greenhouse pepper plant diseases. Depending on the species and stage of phenology, light application at night may be problematic (i.e., in order to induce or prevent plants from entering the flowering, fruiting, or stem extension stages) (Strasburger 1991). Here, more research would be required in the use of light-adapted fluorescence parameters such as $\left(\mathrm{F}_{\mathrm{m}}^{\prime}-\mathrm{F}_{\mathrm{o}}^{\prime}\right) / \mathrm{F}_{\mathrm{m}}^{\prime}$, whereby the classification threshold is likely to depend on the locally absorbed PAR of plant leaves. The locally absorbed PAR is highly dependent on incoming light geometry, leaf angle, and leaf absorbance, making its precise estimation difficult. However, there may be a certain time period around dawn where the $\left(\mathrm{F}_{\mathrm{m}}^{\prime}-\mathrm{F}_{\mathrm{o}}^{\prime}\right) / \mathrm{F}_{\mathrm{m}}^{\prime}$ threshold is relatively insensitive to (low) PAR. Using supplemental NIR and a shading box, a relatively short relaxation time for $\mathrm{F}_{\mathrm{m}}^{\prime}$ and $\mathrm{F}_{\mathrm{o}}^{\prime}$, which is the time needed to approach their dark-adapted values $\left(\mathrm{F}_{\mathrm{m}}\right.$ and $\left.\mathrm{F}_{\mathrm{o}}\right)$, may prolong this suitable time frame, facilitating detection.

Measurements in the field would be an even more challenging endeavor, due to problems such as supplying the whole acreage with electricity or the need for typically higher excitation intensities to estimate $\mathrm{F}_{\mathrm{m}}$. In spite of these problems, an overnight vehicle carrying the box along the whole acreage and placing it over a number of plants for taking measurements is nonetheless conceivable. A first approach using a manually driven vehicle has already been implemented by Polder et al. (2014), who used it to detect the Tulip breaking virus in tulip fields.

Variables that do not need dark-adapted plants could be measured without a box but changing light conditions would pose a serious problem in this situation. In sunny conditions, for example, it would be very difficult to differentiate between plants and soil because the contrast between light and shadow is usually higher than that between plant and soil (Sandmann et al. 2013). In the absence of the box, leaf movements induced by air flow would impede the optimal focus of the images and cause image processing problems. Another advantage of taking measurements in the field at night is that there is a lower probability of near-ground air flow at that time of day.

Table 7. Discrimination of plants that were diseased during the experiment, using the two-dimensional discriminant function ${ }^{\mathrm{a}}$

\begin{tabular}{lccccc}
\hline DAFS & Plants & Diseased & Healthy & Right class & Wrong class \\
\hline-3 & 5 & 0 & 5 & 1.00 & 0.00 \\
-2 & 18 & 0 & 18 & 1.00 & 0.00 \\
-1 & 29 & 5 & 24 & 0.83 & 0.17 \\
0 & 34 & 29 & 5 & 0.85 & 0.15 \\
1 & 27 & 27 & 0 & 1.00 & 0.00 \\
2 & 12 & 12 & 0 & 1.00 & 0.00 \\
3 & 5 & 4 & 1 & 0.80 & 0.20 \\
\hline
\end{tabular}

${ }^{\text {a }}$ Daily values from days after first symptoms (DAFS) $=-3$ to 3 , where 0 is the day when symptoms of the infection became visible, -3 is 3 days earlier and 3 is 3 days later. Plants $=$ number of plants observed, right and wrong class $=$ relative proportion of correctly or incorrectly assigned class memberships.
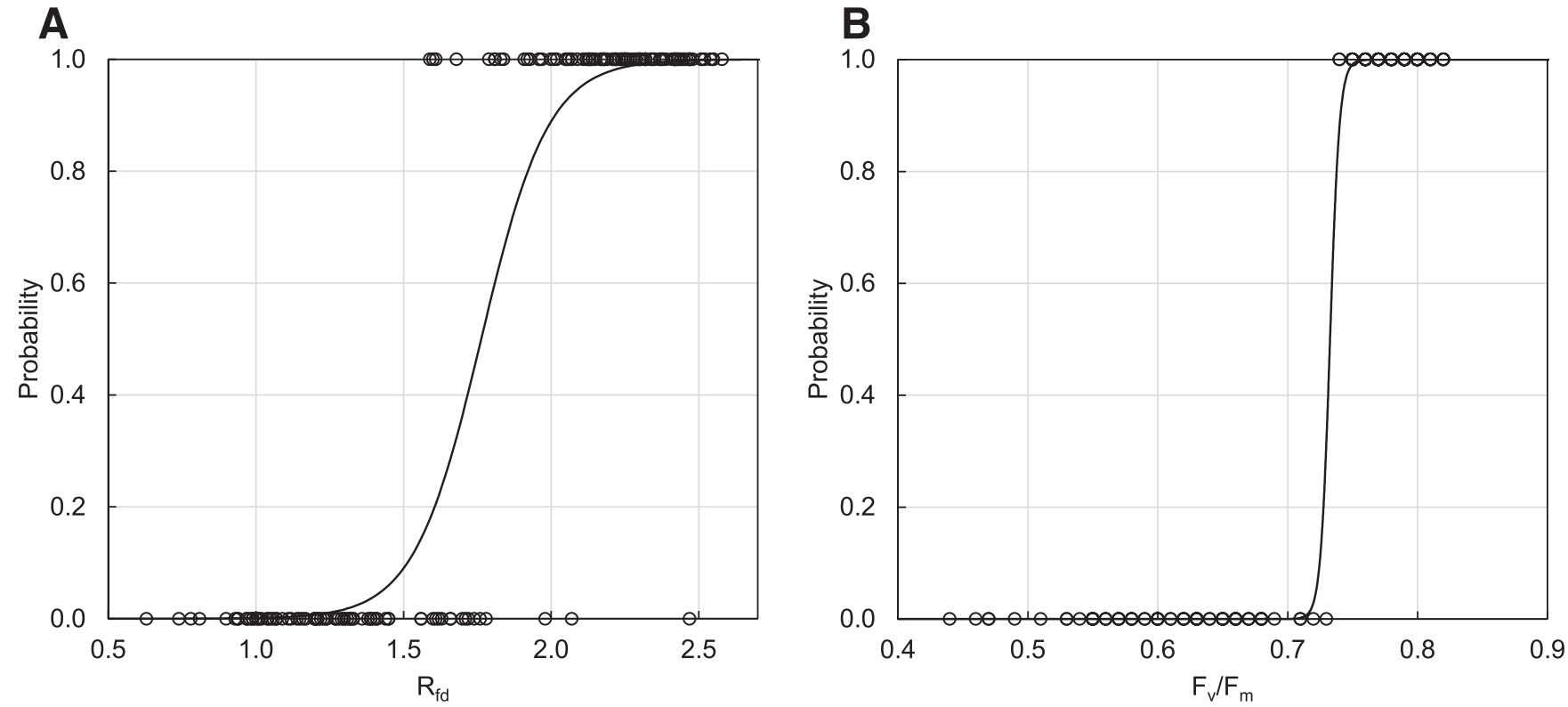

Fig. 4. Logistic regression functions for $A$, fluorescence decline ratio in steady state $\left(R_{f d}\right)$ and $B$, photosystem II maximum quantum yield $\left(F_{v} / F_{m}\right)$, where a probability of 1 indicates healthy plants and a probability of 0 indicates diseased plants. Circles $=$ plants observed and solid line = logistic regression function using the parameters from Table $6 ; n=191$. 
It can be summarized from our study that the nondestructive detection of $R$. solani in young lettuce plants can be achieved under controlled environmental conditions with a high degree of certainty. The future transition of this method into horticultural practice is conceivable from a technical point of view. However, a number of technical developments and additional experiments in greenhouses and in the field would be necessary to achieve this objective.

\section{Literature Cited}

Adam, M., Westphal, A., Hallmann, J., and Heuer, H. 2014. Specific microbial attachment to root knot nematodes in suppressive soil. Appl. Environ. Microbiol. 80:2679-2686.

Bauriegel, E., and Herppich, W. B. 2014. Hyperspectral and chlorophyll fluorescence imaging for early detection of plant diseases, with special reference to Fusarium spec. infections on wheat. Agriculture 4:32-57.

Belasque, J., Gasparoto, M. C. G., and Marcassa, L. G. 2008. Detection of mechanical and disease stresses in citrus plants by fluorescence spectroscopy. Appl. Opt. 47:1922-1926.

Belin, É., Rousseau, D., Boureau, T., and Caffier, V. 2013. Thermography versus chlorophyll fluorescence imaging for detection and quantification of apple scab. Comput. Electron. Agric. 90:159-163.

Berdugo, C., Zito, R., Paulus, S., and Mahlein, A. K. 2014. Fusion of sensor data for the detection and differentiation of plant diseases in cucumber. Plant Pathol. 63:1344-1356

Boccara, M., Boué, C., Garmier, M., De Paepe, R., and Boccara, A. C. 2001. Infrared thermography revealed a role for mitochondria in pre-symptomatic cooling during harpin-induced hypersensitive response. Plant J. 28:663-670.

Bongiovanni, R., and Lowenberg-DeBoer, J. 2004. Precision agriculture and sustainability. Precis. Agric. 5:359-387.

Calderón, R., Navas-Cortés, J. A., Lucena, C., and Zarco-Tejada, P. J. 2013. Highresolution airborne hyperspectral and thermal imagery for early detection of Verticillium wilt of olive using fluorescence, temperature and narrow-band spectral indices. Remote Sens. Environ. 139:231-245.

Cassman, K. G. 1999. Ecological intensification of cereal production systems: Yield potential, soil quality, and precision agriculture. Proc. Natl. Acad. Sci. USA 96:5952-5959.

Chaerle, L., Hagenbeek, D., De Bruyne, E., Valcke, R., and Van der Straeten, D. 2004. Thermal and chlorophyll-fluorescence imaging distinguish plantpathogen interactions at an early stage. Plant Cell Physiol. 45:887-896.

Chaerle, L., Hagenbeek, D., De Bruyne, E., and Van Der Straeten, D. 2007a. Chlorophyll fluorescence imaging for disease-resistance screening of sugar beet. Plant Cell Tissue Organ Cult. 91:97-106.

Chaerle, L., Leinonen, I., Jones, H. G., and Van Der Straeten, D. 2006. Monitoring and screening plant populations with combined thermal and chlorophyll fluorescence imaging. J. Exp. Bot. 58:773-784.

Chaerle, L., Lenk, S., Hagenbeek, D., Buschmann, C., and Van Der Straeten, D. 2007b. Multicolor fluorescence imaging for early detection of the hypersensitive reaction to Tobacco mosaic virus. J. Plant Physiol. 164:253-262.

Chaerle, L., Van Caeneghem, W., Messens, E., Lambers, H., Van Montagu, M., and Van Der Straeten, D. 1999. Presymptomatic visualization of plant-virus interactions by thermography. Nat. Biotechnol. 17:813-816.

Costa, J. M., Grant, O. M., and Chaves, M. M. 2013. Thermography to explore plant-environment interactions. J. Exp. Bot. 64:3937-3949.

Cséfalvay, L., Di Gaspero, G., Matouš, K., Bellin, D., Ruperti, B., and Olejníčková, J. 2009. Pre-symptomatic detection of Plasmopara viticola infection in grapevine leaves using chlorophyll fluorescence imaging. Eur. J. Plant Pathol. 125:291-302.

Daley, P. F. 1995. Chlorophyll fluorescence analysis and imaging in plant stress and disease. Can. J. Plant Pathol. 17:167-173.

Erlacher, A., Cardinale, M., Grosch, R., Grube, M., and Berg, G. 2014. The impact of the pathogen Rhizoctonia solani and its beneficial counterpart Bacillus amyloliquefaciens on the indigenous lettuce microbiome. Front. Microbiol. 5:175.

Feller, C., Bleiholder, H., Buhr, L., Hack, H., Hess, M., Klose, R., Meier, U., Stauss, R., Boom, T. d., and Weber, E. 1995. Phanologische Entwicklungsstadien von Gemusepflanzen I. Zwiebel-, Wurzel-, Knollen- und Blattgemuse. Nachrichtenbl. Dtsch. Pflanzenschutzdienstes 47:193-205.
Gonzalez, R. C., Eddins, S. L., and Woods, R. E. 2010. Digital Image Processing Using MATLAB, Dorling Kindersley, London.

Greenberg, J. T. 1997. Programmed cell death in plant-pathogen interactions Annu. Rev. Plant Biol. 48:525-545.

Grosch, R., and Kofoet, A. 2003. Influence of temperature, $\mathrm{pH}$ and inoculum density on bottom rot on lettuce caused by Rhizoctonia solani (Einfluss von Temperatur, $\mathrm{pH}$ und Inokulumdichte auf die Salatfäule verursacht durch Rhizoctonia solani ). Z. Pflanzenkrankh. Pflanzenschutz (J. Plant Dis. Prot.) 110:366-378.

Grosch, R., Schneider, J. H., Kofoet, A., and Feller, C. 2011. Impact of continuous cropping of lettuce on the disease dynamics of bottom rot and genotypic diversity of Rhizoctonia solani AG 1-IB. J. Phytopathol. 159:35-44.

Huang, J. F., and Apan, A. 2006. Detection of Sclerotinia rot disease on celery using hyperspectral data and partial least squares regression. J. Spat. Sci. 51:129-142.

Iqbal, M., Goodwin, P., Leonardos, E., and Grodzinski, B. 2012. Spatial and temporal changes in chlorophyll fluorescence images of Nicotiana benthamiana leaves following inoculation with Pseudomonas syringae pv. tabaci. Plant Pathol. 61:1052-1062.

Jones, H. G. 1999. Use of infrared thermometry for estimation of stomatal conductance as a possible aid to irrigation scheduling. Agric. For. Meteorol. 95:139-149.

Kozlovskii, F. I., Rühlmann, J., Travnikova, L. S., and Kuzyakov, Y. V. 2001. Clay differentiation in initially homogeneous substrates upon long-term field experiments. Eurasian Soil Sci. 34:130-138

Lindenthal, M., Steiner, U., Dehne, H.-W., and Oerke, E.-C. 2005. Effect of downy mildew development on transpiration of cucumber leaves visualized by digital infrared thermography. Phytopathology 95:233-240.

Lloyd, S. 1982. Least squares quantization in PCM. IEEE Trans. Inf. Theory 28:129-137.

Mahlein, A.-K., Oerke, E.-C., Steiner, U., and Dehne, H.-W. 2012. Recent advances in sensing plant diseases for precision crop protection. Eur. J. Plant Pathol. 133:197-209.

McBratney, A., Whelan, B., Ancev, T., and Bouma, J. 2005. Future directions of precision agriculture. Precis. Agric. 6:7-23.

Muhammed, H. H. 2005. Hyperspectral crop reflectance data for characterising and estimating fungal disease severity in wheat. Biosyst. Eng. 91:9-20.

Muniz, C., Freire, F., Viana, F., Cardoso, J., Sousa, C., Guedes, M., van der Schoor, R., and Jalink, H. 2014. Monitoring cashew seedlings during interactions with the fungus Lasiodiplodia theobromae using chlorophyll fluorescence imaging. Photosynthetica 52:529-537.

Nilsson, H. E. 1991. Hand-held radiometry and IR-thermography of plant-diseases in field plot experiments. Int. J. Remote Sens. 12:545-557.

Oerke, E., Steiner, U., Dehne, H., and Lindenthal, M. 2006. Thermal imaging of cucumber leaves affected by downy mildew and environmental conditions. J. Exp. Bot. 57:2121-2132.

Polder, G., van der Heijden, G. W., van Doorn, J., and Baltissen, T. A. 2014 Automatic detection of tulip breaking virus (TBV) in tulip fields using machine vision. Biosyst. Eng. 117:35-42.

PSI. 2012. FluorCam Instruction Manual Version 2.0. Photon Systems Instruments, Brno, Czech Republic.

Sandmann, M., Graefe, J., and Feller, C. 2013. Optical methods for the nondestructive estimation of leaf area index in kohlrabi and lettuce. Sci. Hortic. (Amsterdam) 156:113-120.

Sankaran, S., Mishra, A., Ehsani, R., and Davis, C. 2010. A review of advanced techniques for detecting plant diseases. Comput. Electron. Agric. 72:1-13.

SAS Institute. 2008. SAS/STAT 9.2 User's Guide. SAS Institute, Inc., Cary, NC.

Schneider, J., Schilder, M., and Dijst, G. 1997. Characterization of Rhizoctonia solani AG 2 isolates causing bare patch in field grown tulips in the Netherlands. Eur. J. Plant Pathol. 103:265-279.

Scholes, J. D., and Rolfe, S. A. 2009. Chlorophyll fluorescence imaging as tool for understanding the impact of fungal diseases on plant performance: A phenomics perspective. Funct. Plant Biol. 36:880-892.

Schor, N., Berman, S., Dombrovsky, A., Elad, Y., Ignat, T., and Bechar, A. 2017. Development of a robotic detection system for greenhouse pepper plant diseases. Precis. Agric. 18:394-409.

Strasburger, E. 1991. Lehrbuch der Botanik, 33. Gustav Fischer Verlag, Stuttgart, Jena, New York.

Tatagiba, S. D., DaMatta, F. M., and Rodrigues, F. Á. 2015. Leaf gas exchange and chlorophyll a fluorescence imaging of rice leaves infected with Monographella albescens. Phytopathology 105:180-188. 